\title{
Imagens da justiça, currículo e educação jurídica: um olhar sobre as questões de gênero e sexualidade
}

\section{Images of justice, curriculum and legal education: a view on gender and sexuality issues}

\author{
Dra. Maria Cecilia Lorea Leite (PPGE/UFPel $)^{1}$ \\ Dr. Renato Duro Dias (PPGD/FURG) ${ }^{2}$
}

\begin{abstract}
Resumo: Este artigo analisa imagens da justiça elaboradas por estudantes do curso de Direito com ênfase nas questões de gênero e sexualidade. $O$ objetivo desta pesquisa foi, sobretudo, trazer contribuições para a análise do currículo de um curso jurídico. Investigou-se o currículo do curso e selecionou-se uma imagem produzida por estudantes iniciantes. A metodologia proposta para este trabalho foi o método documentário, com base, principalmente, em Ralf Bohnsack. A fim de problematizar como se conformou a modelagem curricular do curso de Direito, propôs-se a resenha histórica, bem como se referenciou alguns estudos neste campo. Estudou-se questões relativas à análise de imagens de justiça, que se traduzem como importantes para discutir o currículo do curso jurídico em análise, bem como para as questões de gênero e de sexualidade. Para finalizar, produziu-se reflexão sobre a imagem de justiça analisada, pensando contribuir sobre as questões de gênero e sexualidade que se encontram nos discursos do curso, da mídia e da sociedade.
\end{abstract}

Palavras-chave: Currículo; Curso de Direito; Imagens da justiça; Gênero e Sexualidade.

Abstract: This paper discusses research data on images of justice elicited from students of a law program, focusing on gender and sexuality issues in order to contribute with elements for the analysis of the law school curriculum and its pedagogy. The law program curriculum was analyzed and an image produced by one of the first-year students was selected. The methodology used to carry out this study was the documentary method, based mainly on Ralf Bohnsack's work. Some topics have been included for the purpose of elucidating how the law school curriculum model has been shaped up to the present day. Issues referring to the analysis of images of justice, which are thought of as relevant for curriculum and legal pedagogy understanding, as well as gender and sexuality issues, have been addressed. Finally, a reflection on the selected image of justice, seeking to contribute to the reading of speeches generated in everyday academic and media contexts, was developed.

Keywords: Curriculum; Legal Pedagogy; Images of justice; Gender and Sexuality.

\footnotetext{
${ }^{1}$ Professora da Faculdade de Educação e do Programa de Pós-Graduação em Educação da Universidade Federal de Pelotas (UFPel). Possui graduação em Direito e Licenciatura Plena em Letras, Mestrado e Doutorado em Educação. Realizou Pós Doutorado na Université Paris 8

2 Professor da Faculdade de Direito, do Programa de Pós- Graduação em Direito - Mestrado em Direito e Justiça Social - e da Especialização em Educação em Direitos Humanos da Universidade Federal do Rio Grande (FURG). Atualmente é Coordenador dos Cursos de Direito da FURG e do Centro de Referência em Direitos Humanos (CRDH/FURG). Doutor em Educação com período sanduíche na Universidade de Lisboa, Portugal
} 


\section{Introdução}

Nos últimos anos há um incremento no campo de estudos sobre a problemática do ensino jurídico e suas interfaces com as inovações pedagógicas e as exigências das Diretrizes Curriculares Nacionais no Brasil (Rodrigues, 2005; Leite, 2003, 2004; Santos e Morais, 2007; Nalini e Carlini, 2010; Bittar, 2005; Fragale Filho, 2004; Henning, 2008: Dias, 2014), os quais têm propiciado relevantes aportes para o debate sobre revisões curriculares e pedagógicas do curso de Direito em nosso país. Visando contribuir nessa direção e tendo em conta os dados de uma investigação mais ampla sobre imagens da justiça produzidas por acadêmicos do curso de Direito, buscar-se-á neste artigo analisar uma dessas imagens, com foco em questões de gênero e de sexualidade, com o objetivo de refletir sobre alguns elementos para a análise do currículo jurídico e de sua pedagogia.

É importante registrar que a proposição deste trabalho inspira-se, ainda, em experiências desenvolvidas em outros estudos sobre imagens, como, por exemplo, imagens da justiça em séries televisivas, bem como na literatura e no cinema (Villez, 2010; Ambroise-Rendu, Sécail, 2010; Garapon, Salas, 2008), imagens do crime na televisão (Sécail, 2010); imagens docentes (Leite, Hypolito, Loguércio, 2010), imagens de escolas (Alves, Oliveira, 2004).

Com base nesses estudos, entendemos que é possível analisar as produções acadêmicas sobre imagens da justiça do ponto de vista pedagógico. Igualmente, buscar compreender a pedagogia jurídica desenvolvida através do currículo proposto pela Faculdade de Direito, e de que forma esta matriz curricular acaba por se entrecruzar com os contextos socioculturais e informativos em que os bacharelandos em Direito vivem.

Compreendemos que a partir das imagens é possível constatar uma ampla gama de aspectos culturais que perpassam o currículo e suas conformações, dentre estas, para este artigo, selecionamos um recorte que pretende examinar os entrelaçamentos com questões de gênero e de sexualidade. Estas últimas assumiram uma evidente centralidade na contemporaneidade. Entendemos que os temas referentes a gênero e a sexualidade estão presentes, como observa Ribeiro (2007, p. 3), tanto na mídia, como "nos discursos médico, jurídico, educacional, entre outros".

No entanto, no campo da ciência do Direito e do Ensino jurídico tem-se abordado muito pouco as questões referentes a gênero e a sexualidade, e, muitas vezes, quando isto ocorre, estas são tratadas de forma limitada e superficial, a ponto de a análise ocorrer de forma independente do próprio contexto em que se inserem. Entendemos ser da maior relevância investigar esta temática, principalmente, do ponto de vista dos direitos humanos e da cidadania, já que as questões de gênero e sexualidade têm gerado muitas controvérsias entre professores, alunos e juristas, causando certo 'mal estar' acadêmico e, por assim dizer, imprimido uma limitação na aplicação de um direito tão elementar quanto o direito de 'ser' 3 .

Dados estatísticos apontam o Brasil como um dos países no qual os homossexuais e os transexuais, masculinos e femininos sofrem extrema violência (Grupo Gay da Bahia ${ }^{4}$ ). Com

\footnotetext{
${ }^{3}$ DIAS, Renato Duro. "As uniões homoafetivas: um estudo sobre as formas de (re)pensar os direitos dos homossexuais", 2011.

${ }^{4}$ http://www.ggb.org.br/
} 
índices alarmantes, igualmente para as mulheres, a sociedade brasileira retrata arquétipos machistas, heterosexistas e dominadores, já que raros são os dias em que a mídia não veicula um assassinato violento ou uma cena de agressão física e psicológica contra a mulher.

Uma das portas que tem levado à violência é a homofobia e a não aceitação das sexualidades 5 . Outra, sem dúvida, é a cultura de dominação imposta por referenciais conservadores. Guacira Louro $^{6}$, ao abordar as identidades sobre o prisma do 'normal' e do 'diferente', adverte para importância de se voltar para práticas que "desestabilizam e desconstruam a naturalidade, a universalidade e a unidade do centro e que reafirmem o caráter construído, movente e plural de todas as posições"?.

Defendemos que a escola, em todos os níveis, e, no caso do presente estudo, o próprio ensino superior em Direito pode ser um excelente espaço de construção destas multiplicidades e, por assim dizer, de movimentos e mudanças em prol das questões de gênero e de sexualidade.

Elegemos como metodologia, a análise de imagens segundo o método documentário de interpretação, de forma a propiciar o exame de como são mostradas as percepções sobre gênero e sexualidade em uma das imagens da justiça selecionada para este trabalho, produzida por um dos alunos ingressantes de uma Faculdade de Direito do sul do Brasil.

Este recorte foi realizado a partir das imagens que coletamos entre grupos de estudantes do primeiro e do último ano da mesma Faculdade de Direito. Pensamos que a imagem selecionada reflete parte deste conjunto e contexto de alunos ingressantes, cujas imagens se apresentam com forte diálogo com questões culturais.

Neste sentido, nossa pesquisa foi matizada pela voluntariedade, já que se propôs aos estudantes que concordaram em participar da investigação ${ }^{8}$, que elaborassem um desenho sobre imagens da justiça. Além disso, foi solicitado aos estudantes que, após a realização do trabalho proposto, fizessem uma breve descrição sobre os possíveis significados e representações daquela criação imagética. Então, na maior parte do conjunto das imagens de justiça, esteve também presente uma linguagem de descrição.

A análise desenvolvida teve como principais referenciais teóricos os estudos de Ralf Bohnsack (2007; 2010), no que se refere ao método documentário de interpretação, e de Philippe Dubois (2010) e de Martine Joly (2007), propiciando examinar a particularidade da imagem em contraposição ao texto. Tal metodologia, que é própria das Ciências Sociais, registra em sua origem uma reciprocidade de influências entre essa área e os métodos da História da Arte, especialmente a iconologia, iconografia e a semiologia.

Assim, procurar-se-á analisar a imagem da justiça eleita para este estudo a partir da reconstrução de suas estruturas formais, na perspectiva de captar seu sentido particular, com especial foco no conceito de imagem como índice ${ }^{9}$.

\footnotetext{
${ }^{5}$ DIAS, Renato Duro. Ibid.

${ }^{6}$ LOURO, Guacira Lopes. "Currículo, gênero e sexualidade. O 'normal', o ‘diferente' e o 'excêntrico”, 2003.

${ }^{7}$ LOURO, Guacira Lopes. Ibíd., p.53

${ }^{8}$ A participação na pesquisa era voluntária.

${ }^{9}$ DUBOIS, Philippe, O ato fotográfico e outros ensaios. 2010.
} 
Para tal, estruturamos nosso artigo em três momentos. Na primeira parte do texto procuramos (des) pensar o ensino do direito e a pedagogia jurídica, a partir de reflexões teóricas de estudiosos da área, com foco especial no currículo. Assim, propomos uma breve síntese histórica, resgatando alguns tópicos na perspectiva de evidenciar como se conformou a modelagem curricular do curso de Direito até os dias atuais. A seguir, abordamos outro campo significativo do saber, que é o da análise de imagens de justiça, no qual entendemos ser relevante para compreensão dos estudos sobre currículo e pedagogia jurídica, já que nos possibilitam um olhar plural e distinto do texto. Em conjunto com esta análise de imagens escolhemos como recorte as questões de gênero e de sexualidade, tema relevante para quem entende propor um ensino jurídico capaz de ser significativamente multicultural. Por fim, refletimos sobre uma imagem de justiça e a partir dela buscamos compreender como esta trama curricular pode nos ser útil na leitura dos discursos engendrados no cotidiano acadêmico, familiar e midiático.

\section{Currículo e Ensino do Direito}

Constatamos que o ensino jurídico no Brasil, nas duas últimas décadas, tem sido alvo de análises, processos de avaliação, reformas curriculares, bem como objeto de manifestações controversas nos meios de comunicação, em especial quando se trata de abordar os índices de reprovação nos exames de Ordem e a baixa qualidade na formação dos bacharéis em direito.

Igualmente, identificamos a presença de estudos e pesquisas sobre o ensino jurídico, que evidenciam a necessidade de promover mudanças no contexto curricular do Curso de Direito. (Bastos, 1998; Porto, 2000; Santos, 2002; Van-Dúnem, Leite, 2007).

Conforme assevera Rodrigues ${ }^{10}$, em uma perspectiva histórica, "no período compreendido entre 1827 a 1961 as Faculdades de Direito tinham um mesmo currículo pleno prédeterminado (fixo e rígido), composto por nove cadeiras e com duração de cinco anos". Com a Proclamação da República houve a retirada de algumas destas disciplinas, como por exemplo, Direito Eclesiástico e passam a surgir às disciplinas de Filosofia do Direito e História do Direito ${ }^{11}$.

Nota-se que estas alterações, à época, refletiram anseios desde a criação do primeiro curso de Direito, em São Paulo, em 1827, já que de acordo com Santos e Morais "com a fundação da academia de Direito de São Paulo, os Cursos de Direito, tiveram papel relevante na formação de atores jurídicos dos locais de exercício do poder"12.

Reportando-nos ao movimento de implantação de um novo modelo ensino jurídico ocorrido na década de 1990, com a Portaria Ministerial n. 1.886 de 30 de dezembro de 1994, que possibilitou uma maior autonomia das Universidades e Faculdades para regulamentarem suas estruturas curriculares, observamos que, na prática, houve a permanência de estruturas rígidas, já que na maioria das instituições pouco se flexibilizou em termos curriculares. A par desta

\footnotetext{
${ }^{10}$ RODRIGUES, Horácio Wanderlei, Pensando o Ensino do Direito no Século XXI, 2005, p.61.

${ }^{11}$ RODRIGUES, Horácio Wanderlei, Ibíd., p.62

${ }^{12}$ SANTOS, André Leonardo Copetti e MORAIS, José Luis Bolzan de. O ensino jurídico e a formação do bacharel em Direito: diretrizes político-pedagógicas do curso de direito da UNISINOS, 2007, p.60
} 
rigidez, manteve-se o ensino fragmentado e desconectado com a realidade, imperando um tecnicismo (positivismo ${ }^{13}$ ) conservador.

No plano internacional, observamos que o ensino jurídico está sendo alvo de análises críticas ${ }^{14}$ e debates, entre outros razões, pela vontade de repensar a forma tradicional do ensino jurídico, bem como pelo limitado alcance da Ciência do Direito como elemento de solução dos múltiplos e complexos problemas econômicos e sociais.

Entendemos que um dos desafios dos profissionais educadores que operam o Direito como campo do saber seria o de propiciar condições para que o ensino jurídico supere a distância da realidade social, de forma a responder de forma mais efetiva aos desafios postos por um contexto contemporâneo complexo e permeado de novos conflitos. E, mais, que a ciência jurídica esteja apta a possibilitar a formação de um bacharel: crítico, reflexivo e agente de transformação social.

Repensar ou Des-pensar ${ }^{15}$ os modelos paradigmáticos de ensinagem no Direito, subjazem à proposta de investigação à qual se vincula este trabalho, já que identificamos, como fundamental, o acesso à cultura jurídica por parte dos cidadãos, na perspectiva de contribuir para o processo de democratização da sociedade.

Concordamos com Leite ${ }^{16}$, quando esta afirma que o mundo jurídico não está única e exclusivamente ligado a um sistema jurídico formalizado pelo ente Estado, mas que também depende de sua realização como conhecimento válido na sociedade. Por isso, entre outros, depende de sua transmissão, de processos de pedagogização, o que reforça o investimento neste estudo.

Nossa experiência de investigação conflui ainda com relação aos argumentos de Oliveira ${ }^{17}$, na perspectiva de entender a política curricular como uma construção simbólica resultante de relações de poder desencadeadas na esfera cultural. Como bem asseveram Lopes e Macedo, "o currículo torna-se, assim, essa luta política por sua própria significação, mas também pela significação do que vem a ser sociedade, justiça social, emancipação, transformação social"18.

Contribuições teóricas do campo da sociologia da educação e dos estudos culturais nas últimas décadas do século XX enfatizam que o processo educativo não se circunscreve às instituições de ensino. A identificação de diversos contextos de aprendizagem e de suas características (multi) estratificadas, entre eles, a mídia, o cinema, a publicidade, a cultura popular, a publicidade, as comunicações de massa, as instituições religiosas, expandem as possibilidades de compreensão do pedagógico e de seu papel no exterior das instituições tradicionais de ensino aprendizagem. Estes argumentos colocam em causa a produção de novas metodologias e modelos teóricos para analisar a produção cultural, as estruturas e as trocas de conhecimentos ${ }^{19}$. A estes aspectos, articulamos o conceito de Pedagogia Jurídica

\footnotetext{
${ }^{13}$ Ler: BOAVENTURA DE SOUSA, Santos. Para des-pensar o Direito. São Paulo: Cortez, 2000.

${ }^{14}$ SANTOS, André. Ibíd.

${ }^{15}$ SANTOS, André. Ibíd.

${ }^{16}$ LEITE, Maria Cecilia L. "Pedagogia Jurídica e Democracia: possibilidades e perspectivas”, 2004, p.14

${ }^{17}$ OLIVEIRA, Ozerina V. "Tendências teórico-metodológicas em estudos de política curricular: o que dizem teses e dissertações", 2005, p.1

${ }^{18}$ LOPES, Alice C., MACEDO, Elizabeth, Teorias de currículo, 2011, p.253

${ }^{19}$ GIROUX, Henry A, "Praticando Estudos Culturais nas Faculdades de Educação", p.90-91
} 
proposto por Leite ${ }^{20}$ entendido como "o campo do conhecimento que estuda os processos de educação jurídica".

Asseveramos que este campo de conhecimento, tal como outros tantos, se conformam com embates que se desenvolvem nas esferas curriculares, relações entre conhecimento e poder, ora dialogando, ora digladiando-se. Conforme argumentam Antonio Flávio Moreira e Tomaz Tadeu da Silva "o currículo, como campo cultural, como campo de construção e produção de significações e sentido, torna-se, assim, um terreno central dessa luta de transformação das relações de poder" 21 .

Consideramos, assim, que as formas particulares de pedagogias assumidas em diferentes cursos jurídicos podem ser estudadas como práticas semióticas. Estes argumentos ensejam estudos acerca da repercussão das práticas pedagógicas em cursos jurídicos de modo articulado às realizadas em diferentes contextos culturais. Tais formas de pedagogias podem estimular estudos que entrelacem a natureza histórica e socialmente construída dos conhecimentos e experiências, bem como os discursos que contribuem para legitimar e regular diferentes instituições, como a mídia, os cursos de Direito e o sistema judiciário e, assim, contribuírem para pensar a transformação social.

Pensamos que a ação dos educadores pode se constituir como um forte elemento favorável a essa transformação social, pois como lembra Charlot $^{22}$, esta "deve ser acompanhada por uma formação dos educadores, ela mesma profundamente transformada, já que implica o respeito aos princípios de organização democráticos".

Assim, a formação do professor e a capacidade de interlocução docente com o cotidiano escolar são temáticas que envolvem o repensar das práticas pedagógicas para além dos muros escolares. Nestes termos, há que se concordar com Giroux ${ }^{23}$, que compreende o papel do educador e do educando numa relação de troca e de discurso, o qual possibilita a emancipação e a reflexão, posto que os educadores devem ser considerados como intelectuais públicos que estabelecem a ligação entre as ideias críticas, as tradições, as disciplinas e os valores da esfera pública no cotidiano.

Concorre para isso o entendimento da natureza do ensinar, que necessariamente, enquanto atividade social tem como compromisso assegurar que todos aprendam, à medida que a escolaridade contribui para a humanização e, portanto, para a redução das desigualdades sociais. Então, reportamo-nos ao conceito de ensinagem ${ }^{24}$ que parece comportar em si a superação da falsa dicotomia, pois carrega consigo esses compromissos éticos, políticos e sociais da atividade docente para com os alunos, a qual se realiza em determinado espaço institucional e fora dele, como se dá na educação não formal. Assim, pode-se afirmar que

\footnotetext{
${ }^{20}$ LEITE, Maria Cecilia L, "Pedagogia Jurídica e Democracia: possibilidades e perspectivas”, 2004, p.1

${ }^{21}$ MOREIRA, Antonio Flávio e SILVA, Tomaz Tadeu da. (Orgs.). Currículo, cultura e sociedade, 2009, p.30

${ }^{22}$ CHARLOT, Bernard. Texto apresentado no II Fórum Social Mundial pelo Fórum Mundial de Educação, 2003, p.2

${ }^{23}$ GIROUX, Henry A. Qual o papel da Pedagogia Crítica nos estudos de língua e cultura? Uma entrevista com Henry A. Giroux, 2005, p.4

${ }^{24}$ Para o conceito de "Ensinagem" ver PIMENTA, Selma G.; ANASTASIOU, "Léa das Graças Camargo", 2002, pp.203-204
} 
ensinar é um projeto coletivo. Embora cada professor, em sua sala de aula, possua autonomia para desenvolver sua disciplina, esta é parte integrante de um percurso formativo do aluno ${ }^{25}$.

Consideramos que estas questões desafiam o investimento de pesquisas sobre a circulação de imagens e significados, no contexto de cursos jurídicos. Identificamos, no campo do ensino superior, experiências muito significativas de investigação com estudantes universitários. Neste sentido, entende-se que pode ser muito produtivo o estudo das imagens dos estudantes sobre a Justiça e as formas mediante as quais estes se constroem e se inserem no campo profissional e na sociedade. Nesta perspectiva, para o estudo dessas mensagens complexas, são relevantes as contribuições de Dubois ${ }^{26}$ e Joly ${ }^{27}$, as quais propiciam importantes referenciais para a análise de diversas significações das imagens e acerca de problemas levantados por estas quanto à natureza de seus signos.

\section{Imagem de justiça: um olhar sobre as questões de gênero e de sexualidade}

A pesquisa sobre "Imagens da Justiça" nos tem possibilitado a percepção de alguns aspectos que consideramos importantes, contudo, antes, é preciso dizer que este é um olhar recortado. Segundo Alfredo Bosi (1988, p.85) olhar "é um movimento interno do ser que se põe em busca de informações e significações". Para o autor de Fenomenologia do Olhar "o olho (...) se move à procura de alguma coisa, que o sujeito irá distinguir, conhecer ou reconhecer, recortar do contínuo das imagens, medir, definir, caracterizar, interpretar, pensar (...)”.

Esta análise de imagem, vista sobre o recorte das questões de gênero e de sexualidade, baseada no princípio das estruturas simultâneas, exige um trabalho de comparação com outros horizontes ${ }^{28}$. Neste sentido, como foi mencionado, e tendo em conta os limites deste artigo, será realizada uma análise de uma das imagens coletadas, como horizonte comparativo às demais imagens dos estudantes ingressantes.

Considerando a natureza discursiva da imagem, e com base em argumentos de Meneses ${ }^{29}$ e na ideia da imagem como ícone ${ }^{30}$, integramos três modalidades de tratamento na análise: a imagens como registro produzido pelo estudante; a imagem como registro ou parte do observável na faculdade investigada; e, finalmente, a interação entre o estudante e as faculdade/contex to observado (currículo, pedagogia jurídica e dados do estudante-referente).

A interação entre o estudante e a faculdade teve como base de análise o respectivo currículo do curso estudado. Assim, considerou-se que a imagem da justiça apresentada pelo aluno ingressante foi confrontada com os dados gerais relativos ao contexto do aluno e à cultura de sua faculdade, tendo como foco principal as influências da mídia, bem como as nuances

\footnotetext{
${ }^{25}$ PIMENTA, Selma G.; ANASTASIOU, Ibíd.

${ }^{26}$ DUBOIS, Philippe, O ato fotográfico e outros ensaios, 2010.

${ }^{27}$ JOLY, Martine, Introdução à análise da imagem, 2005.

${ }^{28}$ BOHNSACK, Ralf, “A interpretação de imagens e o método documentário”, 2007.

${ }^{29}$ MENESES, Ulpiano T . B., "Fontes visuais, cultura visual, História visual. Balanço provisório, propostas cautelares", 2003.

${ }^{30}$ DUBOIS, Philippe, Ibíd.
} 
socioculturais e econômicos experimentados pelo agente criador da imagem e o seu produto, que chamaremos de 'referente' ${ }^{31}$, já que, segundo Dubois (2010), a imagem como índice possui um valor todo singular ou particular, "pois determinado unicamente por seu referente e só por este: traço de um real" 32 .

\section{A pesquisa e a imagem}

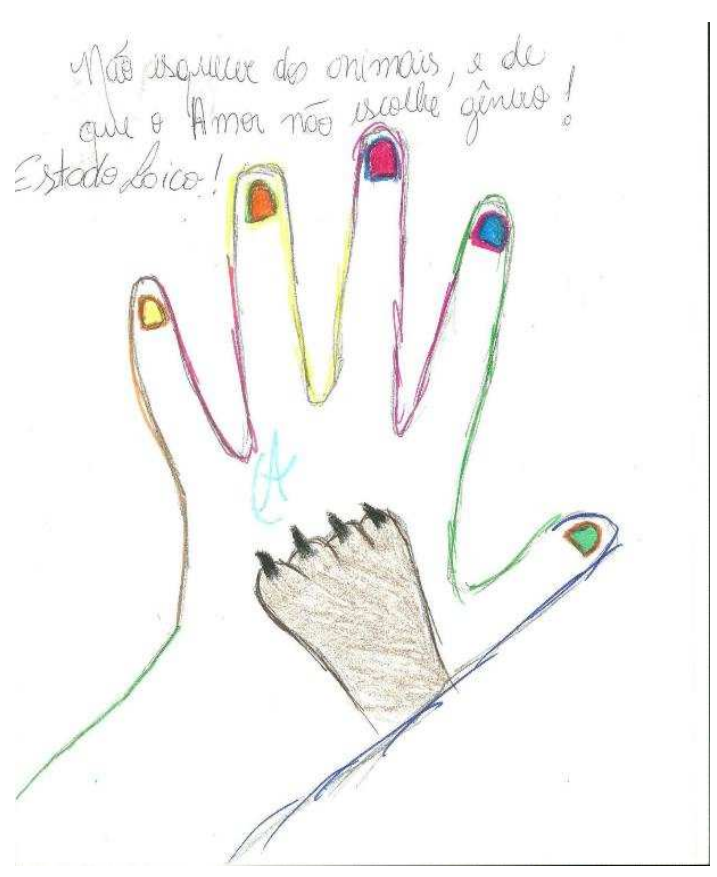

De acordo com a metodologia proposta, aplicamos um formulário de pesquisa (folha em branco) no qual solicitamos aos estudantes que desenhassem imagens da justiça e a partir desta construção imagética, partimos em busca de suas significações. Ressalta-se que foram disponibilizadas canetas coloridas, lápis e giz de cera.

Percebemos que a atividade proposta, construir/desenvolver uma imagem da justiça, teve uma maior adesão das turmas de alunos ingressantes, comparativamente aos concluintes.

Ao fazer estas breves considerações iniciais sobre a aplicação da pesquisa de imagens de justiça com alunos ingressantes e concluintes de uma Faculdade Direito do sul do Brasil, é necessário que se diga que o currículo desta instituição não possui nenhuma disciplina, atividade extracurricular ou estágio, de cunho obrigatório, que enfoque, especificamente, a temática de gênero e de sexualidade. Partindo deste ponto, analisaremos a imagem criada e o seu discurso.

Trata-se, como se percebe pela imagem colacionada, da representação de uma mão esquerda humana aberta, que possui por sobre si uma pata de um animal. Junto à imagem, há o seguinte standard: "Não esquecer dos animais, e de que o Amor não escolhe gênero! Estado Laico!"

Embora nossa análise reflita sobre as questões de gênero e de sexualidade, mister se faz uma pausa a referenciar que a imagem, transmite, ainda, mensagem acerca dos direitos dos animais, temática candente nos novos direitos e que cada vez mais tem merecido atenção de pesquisas ${ }^{33}$ na área do Direito Ambiental. Por ora, para este escrito, nos centraremos nas questões de gênero e de sexualidade.

\footnotetext{
${ }^{31}$ DUBOIS, Philippe, Ibíd.

${ }^{32}$ DUBOIS, Philippe, Ibíd., p.45
}

\footnotetext{
${ }^{33}$ Para mais detalhamento do tema indicamos a obra "O Direito dos Animais: uma abordagem Ética, Filosófica e Normativa”, de Danielle Tetu Rodrigues. Curitiba, Juruá: 2008. 246 p.
} 
Haraway explica de uma maneira geral que o verbete gênero focaliza os escritos das feministas norte-americanas, pois "as posições feministas-socialistas alemãs sobre a sexualização enfatizam a dialética da atuação auto-construtora das mulheres, determinações sociais já estruturadas e re-estruturações parciais" 34 .

A raiz desta palavra em inglês, em francês e, também, em espanhol é o verbo de origem latina generare, que significa, gerar, e cuja alteração do mesmo idioma pode ser gener, donde se pode significar raça ou tipo. Conforme bem demonstra a autora, "os substantivos "Geschlecht", "Gender", "Genre" e "Género" se referem à ideia de espécie, tipo e classe"35.

Em Haraway "as palavras modernas em inglês e alemão, 'Gender' e 'Geschlecht', referem diretamente conceitos de sexo, sexualidade, diferença sexual, geração, engendramento e assim por diante, ao passo que em francês e em espanhol elas não parecem ter esses sentidos tão prontamente" 36 .

A autora entende que "gênero é central para as construções e classificações de sistemas de diferença" 37 . A diferenciação complexa e a mistura de termos para "sexo" e "gênero" são parte da história política das palavras. Neste sentido, os significados que vinculam as categorias raciais e sexuais de gênero parecem apontar para opressões coloniais, racistas e sexuais, todas vinculadas aos sistemas de produção. A importância deste detalhado trabalho refere-se ao fato de que evidencia que as teorias feministas de gênero articulam a opressão das mulheres dentro do contexto cultural onde as diferenciações entre sexo e gênero são marcadamente presentes.

Parece-nos este uma das significações possíveis desta imagem, pois vemos que ao apresentar uma mão aberta que menciona a importância de 'não se esquecer que o Amor não escolhe gênero!', o estudante busca problematizar o contexto em que está inserido, vale dizer uma sociedade machista e heterosexista, permeada de preconceitos que refutam sob qualquer argumento o afeto dentro dos conceitos ditos 'normalizantes', e, desta forma, com sua representação de imagética de justiça, o estudante advoga a preocupação com as formas de exteriorização da afetividade (amor).

Soma-se a esta mão aberta, um multicolorido, que evoca a representação simbólica da diversidade sexual, já que os significados das múltiplas cores correlacionam-se ao próprio análogo arco-íris, que tradicionalmente indica as lutas dos movimentos sociais em defesa dos direitos sexuais ${ }^{38}$.

Desta feita, compreende-se que o estudante quer nos indicar que atualmente só nos é possível entender o conceito de 'Amor' (quiçá relação afetiva ou família), a partir de pressupostos que possam dar conta dos paradigmas pós-modernos e como base de uma estrutura social que privilegie a plenitude do bem estar do ser humano, o que implica em dizer que este 'Amor' deve abranger pelo menos duas pessoas que se unem com o propósito de manutenção deste vínculo afetivo, independente de serem de sexo diverso, tenham ou não prole.

\footnotetext{
${ }^{34}$ HARAWAY, Donna. “'Gênero’ para um dicionário marxista: a política sexual de uma palavra”, 2004, p.207

${ }^{35}$ HARAWAY, Donna. Ibíd., p.209

${ }^{36}$ HARAWAY, Donna. Ibíd

${ }^{37}$ HARAWAY, Donna. Ibíd.

${ }^{38}$ ROUDINESCO, Elisabeth, A família em desordem, 2003
} 
Em verdade, quando a estudante se refere ao estado laico, entende-se que advoga um conceito de sexualidade(s) como alavanca de um bem maior que é a felicidade. Neste aspecto, entendemos que a prole ou a capacidade procriativa não são essenciais para que o relacionamento de duas pessoas mereça proteção legal, o que não se justificaria deixar ao desabrigo do conceito de 'amor' a convivência entre pessoas de mesmo sexo ${ }^{39}$. Aliás, amor, gênero e diferença sexual são termos que seguidamente se entrecruzam.

Como bem lembra Haraway 40 "os significados modernos de gênero se enraízam na observação de Simone de Beauvoir de que "não se nasce mulher". Sendo assim, gênero acaba se desenvolvendo como um conceito feito para "contestar a naturalização da diferença sexual em múltiplas arenas de luta." E, mais, para Haraway ${ }^{41}$ "a teoria e a prática feminista em torno de gênero buscam explicar e transformar sistemas históricos de diferença sexual nos quais "homens" e "mulheres" são socialmente constituídos e posicionados em relações de hierarquia e antagonismo."

É importante dizer que Haraway concorda que "as múltiplas raízes, acadêmicas e de outras instituições, feministas e outras, da categoria literal (escrita) "gênero", fazem parte do sistema de relações hierárquico e que "o poder político e explicativo da categoria "social" de gênero depende da historicização das categorias de sexo, carne, corpo, biologia, raça e natureza" 42 .

Nesta perspectiva, pensamos que os antagonismos universais merecem ser repensados à luz de novas teorias capazes de darem conta de outras articulações possíveis, tanto para o conceito de sexo, como para o de gênero.

Tendemos a concordar com Haraway, pois somente na compreensão articulada da categoria analítica de gênero, com fulcro nos seus processos de construção histórico-sociais é que se poderá romper com as estruturas dominantes em busca de paradigmas emergentes ${ }^{43}$. Já que uma democracia (sexual) somente se produz na atenção a dois princípios: o do direito a igualdade e o do direito às diferenças. ${ }^{44}$

Para não finalizar, gostaríamos de reforçar o standard, Estado Laico, enfatizado pela imagem a que se refere. Aqui, percebemos, segundo análise deste discurso, e em comparação ${ }^{45}$ à imagem construída pelo estudante, que há o entendimento segundo o qual o Estado brasileiro, conforme demonstra nossa Carta Constitucional, deve dispensar tratamento igualitário a todos os credos religiosos, incluso a possibilidade de não crença, sem adotar e sem privilegiar status de oficialidade religiosa a qualquer um deles.

\footnotetext{
${ }^{39}$ DIAS, Renato Duro, Ibíd.

${ }^{40}$ HARAWAY, Donna. Ibíd., p.211

${ }^{41}$ HARAWAY, Donna. Ibíd.,

${ }^{42}$ HARAWAY, Donna. Ibíd., p.246

${ }^{43}$ Parafraseando Boaventura de Sousa Santos.

${ }^{44}$ Boaventura de Sousa Santos. Conferência: "Intolerância: violência e desagregação social”. Grandes Debates. Evento realizado na Assembleia Legislativa do Estado do RS, no dia 09.05.2011.

${ }^{45}$ BOHNSACK, Ralf. Ibíd.
} 


\section{Considerações finais}

A pesquisa com imagens de justiça tem nos possibilitado perceber elementos relevantes relativos ao currículo e ao Curso de Direito. Ao elegermos uma imagem para análise e darmos a ela um tratamento de recorte sobre as questões de gênero e de sexualidade constatamos o quão o currículo pode interferir nos processos de bricolagem do estudante, seja em sua vida acadêmica como no contexto sociocultural que está inserido.

Utilizando nossos referenciais teóricos (Bohnsack, 2007; 2010; Dubois, 2010; Joly, 2007; Santos, 2000) e partindo de temas concretos da vida do aluno (como de fato são as imagens representadas por eles), pensamos poder contribuir para a busca de uma educação reflexiva e crítica, já que estas teorias nos fornecem elementos ao entrelaçamento destes dois mundos comunicantes: ação e conhecimento emancipatório ${ }^{46}$.

A imagem elaborada por um estudante ingressante de um Curso de Direito de uma Faculdade do sul do Brasil, representada por uma mão aberta e multicolorida, nos permite entender que mesmo em uma modelagem curricular tradicional e sem qualquer referenciação teórica sobre as questões de gênero e sexualidade é possível verificar o aporte informativo traduzido pelo aluno.

Pensamos que este aporte seja fruto de um processo de pedagogização desenvolvido por meio de contatos com a mídia e com o contexto no qual este estudante está inserido sócio e culturalmente. Este dado põe em cheque, dentre tantos outros aspectos, o de que o currículo formal é o único agente de formação profissional e acadêmico e mais, que só o currículo oficial é capaz de dar conta de uma gama de latentes questões em territórios totalmente contestados. $^{47}$

Interessa elucidar que a pesquisa com imagens de justiça pode ser um caminho investigativo sobre o currículo, a pedagogia jurídica e o ensino do direito e que com este recorte aqui apresentado nas questões de gênero e de sexualidade se perceba as multiplicidades que tal campo pode contribuir e reflexionar sobre seus nortes.

É o que pretendemos com este escrito. Reflexionar sobre inovações pedagógicas que nos possam fornecer meios aptos a desvendar os infindáveis caminhos traçados pelo dia-a-dia do fazer e da pesquisa docente.

Assim, a pesquisa sobre Imagens de Justiça antes de tudo nos proporcionou uma mudança de olhar sobre o currículo e a pedagogia jurídica. Uma mudança ${ }^{48}$ de prática pedagógica no ensino jurídico e uma mudança na percepção da pedagogia jurídica ${ }^{49}$, começando por pensar numa proposta curricular que viabilize a integração entre os domínios do saber; uma ação

\footnotetext{
46 "O conhecimento emancipatório e pós-moderno a que tenho feito apelo visa descobrir, inventar e promover as alternativas progressistas que essa transformação pode exigir" (SANTOS, 2000, p.167).

${ }^{47}$ SILVA, Tomaz Tadeu da, MOREIRA, Antonio Flavio B., Ibíd.

48 "A discussão paradigmática do direito moderno, em conjunto com a ciência moderna, irá esclarecer os termos e as direções possíveis da transição para um novo paradigma”. Santos (2000, p. 169)

${ }^{49}$ Como bem assevera Leite (2004, p. 16); "Em meu entendimento, a Pedagogia Jurídica necessita dialogar com a Ética, a História e a Política, além da Educação e da Sociologia que se apresenta imprescindíveis, tendo em conta o processo educativo da sociedade exigido pelo Direito e s interesses coletivos em jogo."
} 
reflexiva e crítica do docente no ensino jurídico e, também, uma educação crítica já que esta pode capacitar o aluno (individual e coletivamente), a participar da construção de sua autonomia enquanto sujeito democrático e promover o envolvimento e a identificação destes alunos numa perspectiva emancipadora ${ }^{50}$

Parece ser este um dos possíveis caminhos para a consecução de projetos no ensino jurídico: dar efetividade a uma modelagem curricular plural, primando, sobretudo, pela busca de uma educação crítica, participativa e cidadã.

\section{Referências bibliográficas}

ALVES, Nilda, OLIVEIRA, Inês B. Imagens de escolas: espaços tempos de diferenças no cotidiano. Educação \& Sociedade. 2004, Nº6 , Campinas, SP, pp. 17-36.

AMBROISE-RENDU, Anne-Claude, SÉCAIL, Claire, VILLEZ, Barbara. Présentation. Les Temps de Médias. Revue d'histoire. 2010, N 15, automne, Paris, pp. 6-12.

BASTOS, Aurélio. Ensino jurídico no Brasil. $1^{a}$ ed. Rio de Janeiro: Lumen Júris, 1998. 345p.

BITTAR, Eduardo C. B. O ensino jurídico na pós-modernidade. Anuário ABEDI (Associação Brasileira de Ensino do Direito). 2005, N³ Fundação Boiteux, Florianópolis. $217 \mathrm{p}$.

BOHNSACK, Ralf. A interpretação de imagens e o método documentário. Sociologias. 2007, $\mathrm{N}^{\circ} 18$, Porto Alegre, RS, pp. 286-311,

CHARLOT, Bernard. Texto apresentado no II Fórum Social Mundial pelo Fórum Mundial de Educação. Porto Alegre:, [acesso em $12 \quad$ Marzo 2012] <http://paje.fe.usp.br/ mbarbosa/cursograd/charlot.doc $>$

DIAS, Renato Duro. Relações de poder e controle no currículo do curso de direito da FURG. v. I. Tese de Doutorado. Programa de Pós-Graduação em Educação. Pelotas, UFPel, 2014. 348 .

DIAS, Renato Duro. As uniões homoafetivas: um estudo sobre as formas de (re)pensar os direitos dos homossexuais. In: ALVES DA SILVA, Márcia (Org.). Gênero, Educação, Sexualidade e Conhecimento. Pelotas: Editora da UFPel, 2011, pp. 131-145.

DUBOIS, Philippe. O ato fotográfico e outros ensaios. 13. ed. Campinas, SP: Papirus, 2010. $312 p$.

FRAGALE FILHO, Roberto. Diretrizes curriculares. Anuário ABEDI (Associação Brasileira de Ensino do Direito). 2004, N². Florianópolis: Fundação Boiteux, 2004. pp 45-63. 
GARAPON, Antoine, SALAS, Denis. (Orgs.) Imaginer La Loi. Le droit dans La littérature. Paris: Michalon, 2008. 298p.

GIROUX, Henry A. Praticando Estudos Culturais nas Faculdades de Educação. In: SILVA, Tomaz T. da (Org.). Alienígenas na Sala de Aula: uma introdução aos Estudos Culturais em Educação. Petrópolis, RJ: Vozes, 1995, p. 85-103.

GIROUX, Henry A. Qual o papel da Pedagogia Crítica nos estudos de língua e cultura? Uma entrevista com Henry A. Giroux. Revista Language and Intercultural Communication, 6. Trad. Manuela Guilherme. Porto Alegre, 2005, [acesso em 12 Marzo 2012] Dez. 2005. Disponível em: < http://www.henryagiroux.com/RoleOfCritPedagogy_Port.htm>

HARAWAY, Donna. 'Gênero' para um dicionário marxista: a política sexual de uma palavra. Cadernos Pagu. Campinas, SP, n.22, 2004, p. 201-246.

HENNING, Ana Clara Correa. Conexões entre cultura popular e cultura acadêmica: recontextualização curricular na prática de pesquisa jurídica do curso de direito da Anhanguera Educacional/Faculdade Atlântico Sul em Pelotas. Dissertação de Mestrado, Programa de Pós- Graduação em Educação, Faculdade de Educação. Pelotas, RS, UFPel, 2008. 342p;

JOLY, Martine. Introdução à análise da imagem. Campinas, SP: Papirus, 2005. 218p.

LEITE, Maria Cecilia Lorea. Decisões pedagógicas e inovações no ensino jurídico. v. I. Tese de Doutorado. Programa de Pós-Graduação em Educação. Porto Alegre, UFRGS, 2003. 319p.

LEITE, Denise B. C., SANTIAGO, Rui A., SARRICO, Cláudia, LEITE, Maria Cecilia L., POLIDORI, Marlis M. Student's perceptions on the influence of institucional evaluation on universities. Assessment \& Evaluation in Higher Education. 2006, N6, pp. 625-638, 2006.

, SANTIAGO, Rui A., LEITE, Maria Cecilia L., GENRO, Maria Elly H., BRAGA, Ana Maria S., MOROSINI, Marlis, BROILO, Cecilia L., SARRICO, Cláudia, SANTOS, Izabel. Estudantes e avaliação das universidades: um estudo conjunto Brasil-Portugal. Cadernos de Pesquisa (Fundação Carlos Chagas), 2007, Rio de Janeiro, pp. 661-686,

LEITE, Maria Cecilia L. Pedagogia Jurídica e Democracia: possibilidades e perspectivas. Trabalho apresentado no VIII Congresso Luso Afro Brasileiro de Ciências Sociais. Coimbra, Portugal, Centro de Estudos Sociais, Faculdade de Economia, Universidade de Coimbra, 2004. [Acesso em $1^{\circ}$ março 2012], disponível em: <http://www.ces.uc.pt/lab2004/pdfs/MariaLeite.pdf $>$.

Pedagogia Jurídica: uma inovação necessária. In: MELLO, Elena Maria Billig; COSTA, Fátima Tereza L.da; MOREIRA, Jacira Cardoso. (Orgs.). Pedagogia Universitária: campo de conhecimento em construção. Cruz Alta: UNICRUZ, 2005, p. 355-367. 
Pedagogia Universitária e Ciências Sociais Aplicadas. In: Maria Estela Dal Pai Franco; Elizabeth DiefenthaelerKrahe. (Orgs.). Pedagogia Universitária e Áreas de Conhecimento. Porto Alegre: EDIPUCRS, 2007' p. 161-173.

. ; VAN-DÚNEM, José O. S. Avaliação do Curso de Direito e Inovações. In: GHIGGI, Gomercindo; VAN-DÚNEM, José Octávio S. (Orgs.). Diálogos educativos entre Brasil e Angola. Pelotas: Editora e Gráfica da UFPel, 2007, p. 11-28.

LOPES, Alice C., MACEDO, Elizabeth. Teorias de currículo. São Paulo: Cortez, 2011. 297p.

LOURO, Guacira Lopes. Currículo, gênero e sexualidade. O 'normal', o 'diferente' e o 'excêntrico'. In: LOURO, Guacira Louro et al. (Orgs). Corpo, Gênero e Sexualidade: um debate contemporâneo na educação. Petrópolis: Vozes, 2003. 267p.

MENESES, Ulpiano T . B. de. Fontes visuais, cultura visual, História visual. Balanço provisório, propostas cautelares. Revista Brasileira de História. 2003, ํo45, São Paulo, v. pp. 11-36.

MOREIRA, Antonio Flávio e SILVA, Tomaz Tadeu da. (Orgs.). Currículo, cultura e sociedade. 11. ed. São Paulo: Cortez Editora, 2009.

NALINI, José Renato e CARLINI, Angélica (Coord.) Direitos humanos e formação jurídica. Rio de Janeiro: Forense, 2010. 417p.

OLIVEIRA, Ozerina V. Tendências teórico-metodológicas em estudos de política curricular: o que dizem teses e dissertações. Anais da 28a Reunião Anual da ANPED, Caxambu, 2005, p. 1-18. Disponível em: <www.anped.org.br/reunioes/texto/28/gt12/gt12210int.rtf>

PIMENTA, Selma G.; ANASTASIOU, Léa das Graças Camargo. Docência no Ensino Superior. São Paulo: Cortez, 2002.

PORTO, Inês da Fonseca. Ensino Jurídico: diálogos com a imaginação. Porto Alegre: Fabris, 2000 .

RODRIGUES, Horácio Wanderlei. Pensando o Ensino do Direito no Século XXI. Florianópolis: Fundação Boiteux, 2005. 387p.

ROUDINESCO, Elisabeth. A família em desordem. Rio de Janeiro: Zahar, 2003. 276p.

SANTOS, Boaventura de S. Crítica da Razão Indolente. Contra o desperdício da experiência. Para um novo senso comum: a ciência, o Direito e a política na transição paradigmática. São Paulo: Cortez, 2000. 438p.

SANTOS, André Luiz. Ensino Jurídico: uma abordagem político-educacional. Campinas (SP): Educamp, 2002. 265p. 
SANTOS, André Leonardo Copetti e MORAIS, José Luis Bolzan de. O ensino jurídico e a formação do bacharel em Direito: diretrizes político-pedagógicas do curso de direito da UNISINOS. Porto Alegre: Livraria do Advogado, 2007. 234p.

SÉCAIL, Claire. Le crime à l'écran, Le fait divers criminel à la télévision française (19502010). Paris: INA Éditions; Nouveau Monde Éditions, 2010. 274p.

SILVA, Tomaz Tadeu da; MOREIRA, Antonio Flavio B. (Orgs.). Territórios contestados: $o$ currículo e os novos mapas políticos e culturais. 4. ed. Petrópolis: Vozes, 2001. 286p.

VILLEZ, Bárbara. Television and the legal system. New York: Routledge, 2010. 240p.

VILLEZ, Barbara; SÉCAIL, Claire. Entretien avec Antoine Garapon. LesTemps de Médias. Revue d'histoire, n. 15, automne, 2010, p. 207-215. 